\title{
EXPERIMENTAL INVESTIGATION ON A SOLAR AIR HEATER WITH AND WITHOUT OBSTACLE
}

\author{
A.R.Vijay Babu ${ }^{1}$, M.Kannan ${ }^{2}$, P.M.Venkatesh ${ }^{3}$, N.Bharath Kumar ${ }^{4}$ \\ ${ }^{1}$ Department of Electrical and Electronics Engineering, Vignan Foundation of Science Technology and Research, \\ Guntur, India \\ ${ }^{2}$ Department of Mechanical Engineering,Jayalakshmi Institute of Technology, Thoppur, Salem, India \\ ${ }^{3}$ Department of Electrical and Electronics Engineering, Vignan Foundation of Science Technology and Research, \\ Guntur, India \\ ${ }^{4}$ Department of Electrical and Electronics Engineering, Vignan Foundation of Science Technology and Research, \\ Guntur, India \\ ${ }^{1}$ venkypsg11@gmail.com, ${ }^{2}$ kannanpsg96@gmail.com
}

\begin{abstract}
In this paper convection form of heat transfer is used to convert cold air to hot air. Forced convection is preferred for this experimental analysis; obstacles are also used to analyze the temperature level of air with the help of Air Heating Solar Device (AHSD). Semi Annular fins are used as obstacles for this experimental verification. The outlet temperature and pressure drop of SAH were determined by changing the fin densities with the help of software tool FLUENT. The analysis result shows that the outlet temperature is more and pressure drop was less in the case of SAH with obstacles when compared to the $\mathrm{SAH}$ without obstacles.
\end{abstract}

\section{Keywords- Solar air heater; Pressure drop; Obstacles; CFD analysis; Optimized design}

\section{Introduction}

Plate area of the absorber can increase heat transfer but it leads to increase the pressure, this pressure will be affecting the heat collector. This pressure consuming more power while pumping the heated air in the heat collector end [2]. From the literature survey and review gap plenty of designs were carried out and tested. Ultimately efficiency was achieved with different materials [3-6]. In all the designs researchers were considered plate area, fin materials, absorber and glass with different dimensional design [7-9]. But the efficiency was not attained more than $60 \%$. In this research paper Modified Annular Fins (MAF) with reasonable surface area is using to increase the thermal efficiency.

\section{Implementation of AHSD}

Modified annular fins are used for this implementation, efficiency of this model were improved upto $65 \%$. This model was placed at an altitude of 411 meters height from then sea level. 


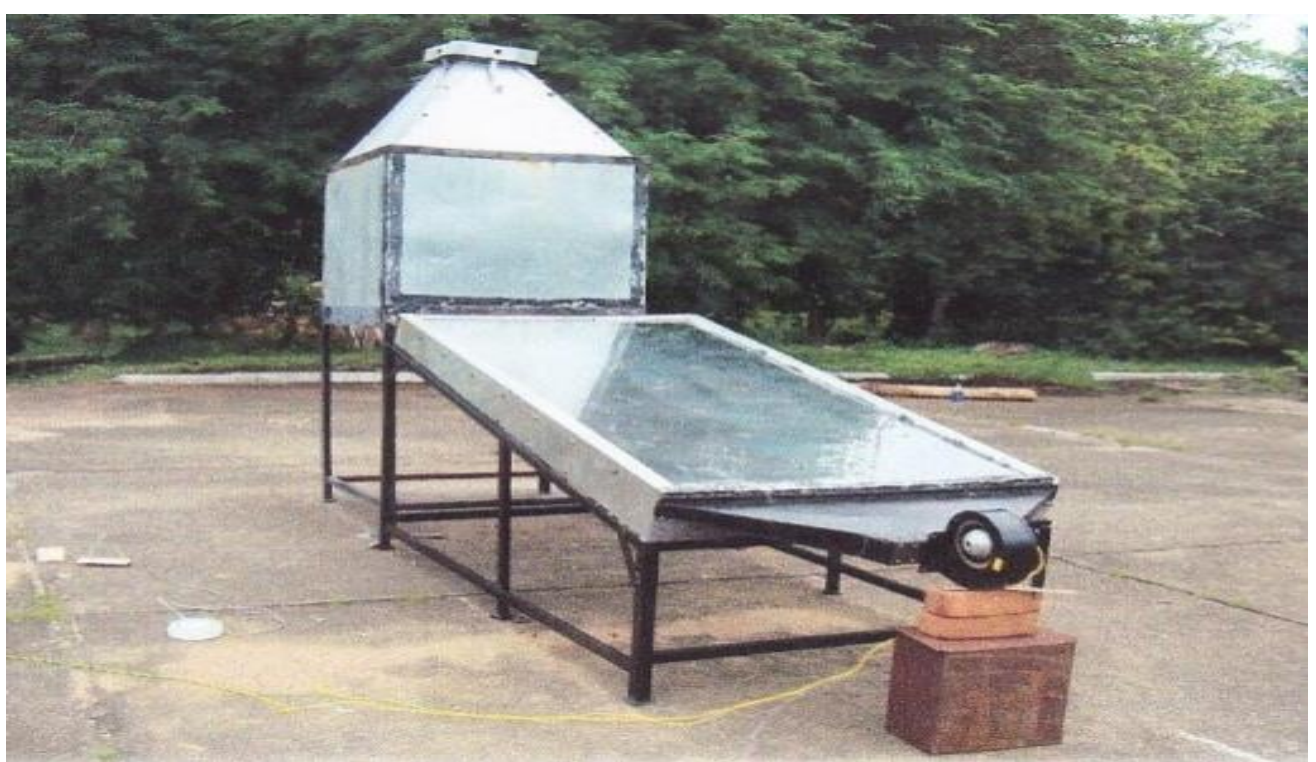

Fig.1. AHSD implementation

Implementation of AHSD and its experimental setup construction is shown in Fig. (1).Modified annular fins and optimized plate for absorber with obstacles is shown in Fig. 2(a) \& 2(b). In this experiment Plates for absorber of two types were used. The plates are made of stainless steel and coated by black chrome. This heat collecting materials is also called heat collectors which both dimensions of (1 x

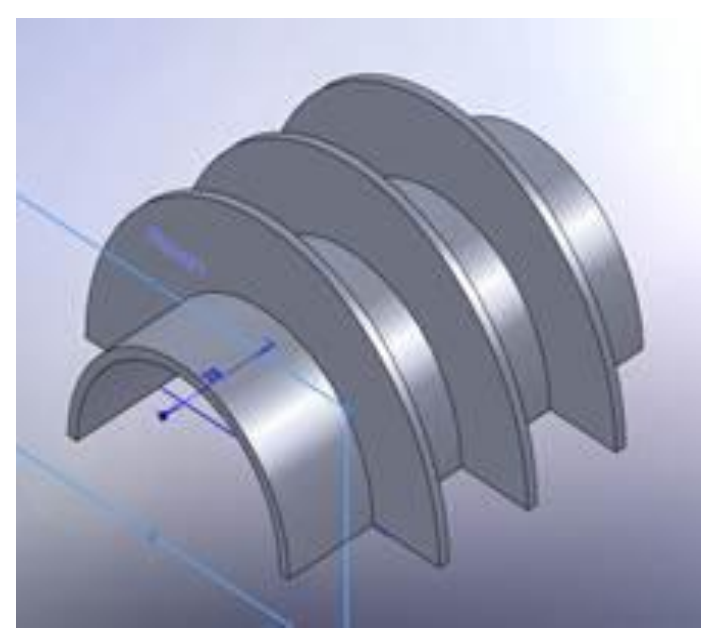

Fig.2. (1)

Modified annular fin

The surface of the absorber is the most important part of the AHSD. It consist of 72 Modified annular fins and stainless steel air flow channels painted by black color and AHSD consist of no fins painted by

Copyright (C) Authors
0.5 x 1) $\mathrm{m}$ respectively. For glazing normal $5 \mathrm{~mm}$ thickness of window glass were used. Single layer of glass cover was used in both the heat collector. The insulation thickness of $40 \mathrm{~mm}$ which leads to increases the heat losses over the heat collector due to conduction. The heat loss due to wind and radiation in the place of insulations are almost zero. Air passage glass and plate for absorber gap is $40 \mathrm{~mm}$.

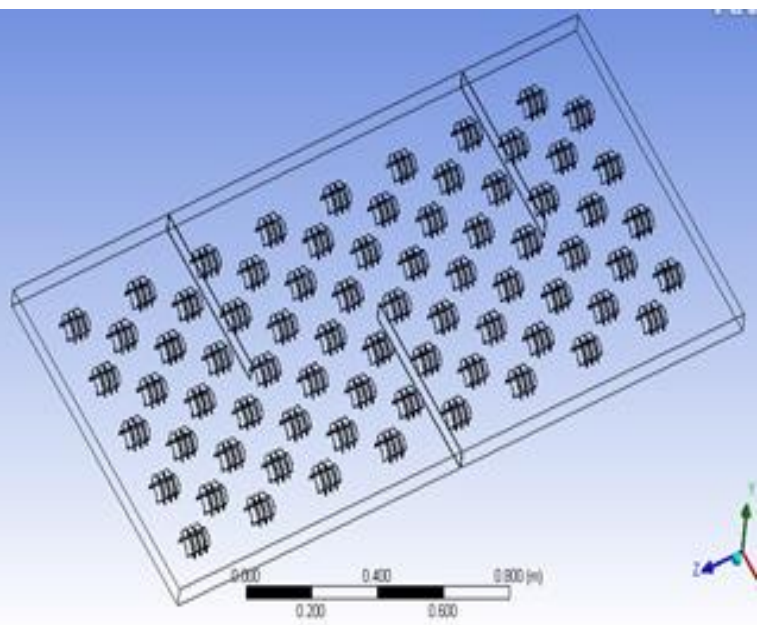

Fig.2. (2)

plate for absorber with obstacles

some different black color. Modified annular fins inner diameter is $0.0188 \mathrm{~m}$ and outer diameter 0.0288 $\mathrm{m}$. In the MAF three more fins were used with the patch of $0.01 \mathrm{~m}$. The distance of 0.25 meters gap is maintained between baffles which is as shown in 
figure 2(1) and 2(2).

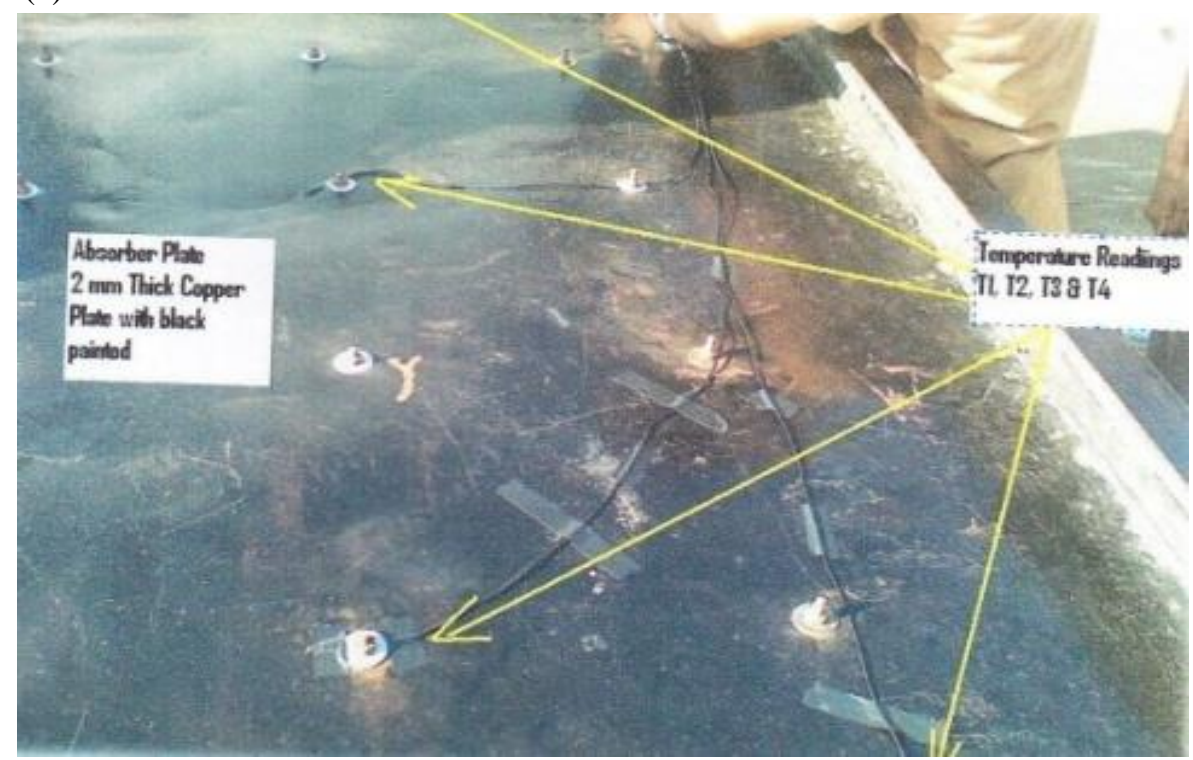

Fig. 3. Thermo coupler and absorber plate

Absorber plates were placed in the top surface in the exact same position along the flow directions, the heat collectors is as shown in figure 3. With the help of two inlet and outlet thermocouples both inlet and outlet temperatures can be measured is as shown in figure 4. The placement of this meter is adjacent to the glass cover which is facing south on the same plane. The values were recorded in the time intervals, the recorded variables such as wind speed, ambient temperature and temperature in the absorber plate in the several locations. Anemometer was used to measure the speed of the wind. In this system fixed speed fan were used to blow the air. The speed of air also adjusted by flaps located in the channel entry.

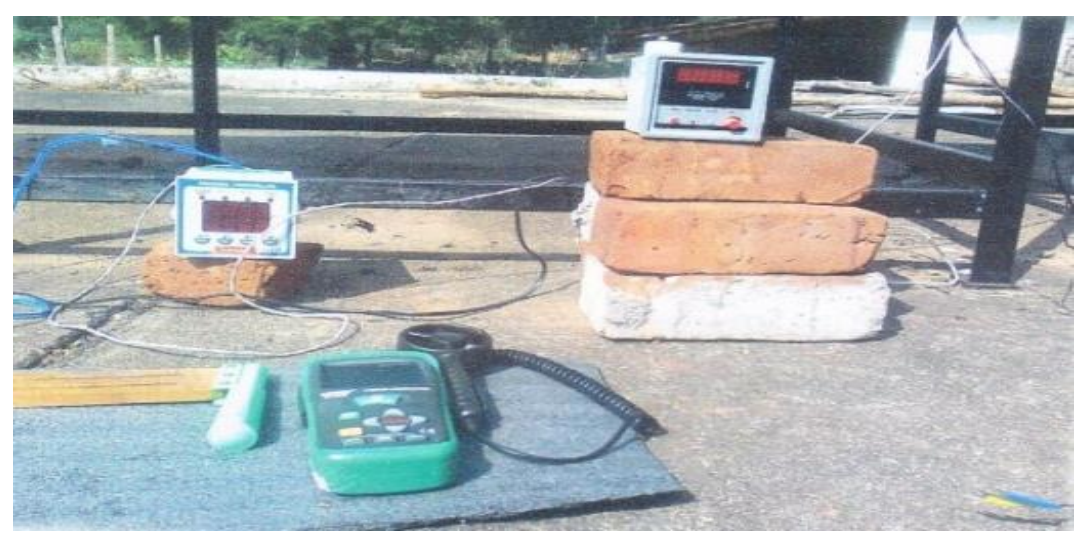

\section{Experimental analysis}

According to the pressure drop limits (25 - $80 \mathrm{~Pa}$ ), the number of fins has been changed in this analysis.

Copyright $($ ) Authors
Fig. 4. Instruments were measured

Initially SAH with baffle arrangement has been designed and analyzed in FLUENT and the results of pressure drop, temperature output, heat transfer rate were got. According to these results the fin densities 
have been changed and the results till the pressure drop of near $80 \mathrm{~Pa}$ was obtained. The initial fin density has been chosen by means of getting the raised temperature is minimum $2{ }^{\circ} \mathrm{C}$ from the temperature raise of $\mathrm{SAH}$ with only baffles arrangement.

Accumulated Energy + Energy Gain = (1)

AbsorbedEnergy + Losses

Accumulated Energy $=\mathrm{M}_{\mathrm{p}} \mathrm{C}_{\mathrm{p}}\left(\frac{\mathrm{dT}_{\eta}}{\mathrm{dt}}\right)$

Energy Gain $=\mathrm{MC}_{\mathrm{p}}\left(\mathrm{T}_{\text {out }}-\mathrm{T}_{\mathrm{in}}\right)$

Absorbed Energy $=\eta_{\mathrm{o}} \mathrm{IA}$

Lost Energy $=\mathrm{U}_{\mathrm{C}}\left(\mathrm{T}_{\mathrm{p}}-\mathrm{T}_{\mathrm{e}}\right) \mathrm{A}_{\mathrm{C}}$

$M_{p} C_{p}\left(\frac{d T_{\eta}}{d t}\right)+M C_{p}\left(T_{\text {out }}-T_{\text {in }}\right)$

$$
=\eta_{\mathrm{o}} \mathrm{IA}_{\mathrm{C}}+\mathrm{U}_{\mathrm{C}}\left(\mathrm{T}_{\mathrm{p}}-\mathrm{T}_{\mathrm{e}}\right) \mathrm{A}_{\mathrm{C}}
$$

Heat Exchanger Effectiveness:

$\varepsilon_{\mathrm{H}}$

$$
=1-\exp \left[-\mathrm{h}_{\text {conv.cot }} * \mathrm{~A}_{\mathrm{S}} /\left(\mathrm{m}_{\text {air.out }} * \mathrm{C}_{\text {p.air }}\right)\right]
$$

Pressure Drop:

$\Delta \mathrm{P}=\Delta \mathrm{P}_{\text {abs }}+\Delta \mathrm{P}_{\text {fric }}-\Delta \mathrm{P}_{\text {buoy }}+\Delta \mathrm{P}_{\text {acc }}$

Collector Efficiency:

$\eta_{\text {col }}=m_{\text {air.out }}-C_{\text {pair }}\left(\mathrm{T}_{\text {air.out }}-\mathrm{T}_{\text {atm }}\right) / \mathrm{I}_{\mathrm{T}} \mathrm{A}_{\mathrm{S}}$

Where,

$$
A_{s}=A_{\text {eff }}+A_{o}
$$

Similarly, the total uncertainty for collector efficiency and

$\left(\mathrm{T}_{\mathrm{a} . i n}-\mathrm{T}_{\mathrm{amb}}\right) / \mathrm{I}$ can be written as:

$$
\begin{aligned}
\mathrm{w}_{\mathrm{R}}=\left(\left(\frac{\partial \mathrm{Rw}_{1}}{\partial \mathrm{x}_{1}}\right)^{2}\right. & +\left(\frac{\partial \mathrm{Rw}_{2}}{\partial \mathrm{x}_{2}}\right)^{2}+\cdots \\
& \left.+\left(\frac{\partial \mathrm{Rw_{ \textrm {n } }}}{\partial \mathrm{x}_{\mathrm{n}}}\right)^{2}\right)^{1 / 2}
\end{aligned}
$$

Following Eq. (11), total uncertainty for mass flow rate can be written as:

$$
\begin{aligned}
& \mathrm{w}_{\mathrm{m}}=\left(\left(\frac{\partial \mathrm{mw}_{\mathrm{F} 1}}{\partial \mathrm{F}_{1}}\right)^{2}\right.+\left(\frac{\partial \mathrm{mw}_{\mathrm{T} 2}}{\partial \mathrm{T}_{2}}\right)^{2} \\
&\left.+\left(\frac{\partial \mathrm{mwP}_{2}}{\partial \mathrm{P}_{2}}\right)^{2}\right)^{1 / 2}
\end{aligned}
$$

Similarly, the total uncertainty for collector efficiency and

$\left(\mathrm{T}_{\mathrm{a} . \mathrm{in}}-\mathrm{T}_{\mathrm{amb}}\right) / I$ can be written as:

$$
\mathrm{w}_{\eta}=\left(\left(\frac{\partial \eta \mathrm{w}_{\mathrm{m}}}{\partial \mathrm{m}}\right)^{2}+\left(\frac{\partial \eta \mathrm{w}_{\mathrm{T}_{\mathrm{az}}}}{\partial \mathrm{T}_{\mathrm{a} . \mathrm{out}}}\right)^{2}\right.
$$

$$
\begin{aligned}
& +\left(\frac{\partial \eta \mathrm{w}_{\mathrm{T}_{\mathrm{a} . \mathrm{in}}}}{\partial \mathrm{T}_{\mathrm{a} . \mathrm{in}}}\right)^{2}+\cdots \\
& \left.+\left(\frac{\partial \eta \mathrm{w}_{\mathrm{I}}}{\partial \mathrm{I}}\right)^{2}\right)^{1 / 2}
\end{aligned}
$$

$\mathrm{W}_{\mathrm{F}}=\left(\left(\frac{\partial \mathrm{FwT}_{\mathrm{a} . \text { in }}}{\partial \mathrm{T}_{\mathrm{a} . \mathrm{in}}}\right)^{2}+\left(\frac{\partial \mathrm{FwT}_{\mathrm{a} . \text { out }}}{\partial \mathrm{T}_{\mathrm{a} . \text { out }}}\right)^{2}+\right.$

$\left.\left(\frac{\partial \mathrm{Fw}_{\mathrm{I}}}{\partial_{\mathrm{I}}}\right)^{2}\right)^{1 / 2}$

where

$F=\left(\mathrm{T}_{\mathrm{a} . \mathrm{in}}-\mathrm{T}_{\mathrm{amb}}\right) / I$

$\Delta P=\frac{m^{2}}{H}\left(\mathrm{C} \mathrm{c}_{\text {fapp }} \mathrm{A}^{*}\right) \frac{\mathrm{L}}{\mathrm{K}}$

Where

$\mathrm{A}^{*}=$ "wetted" heat transfer area / Aperture area of collector

For the flat-plate absorber $A^{*}$ is equal to 2 , for a finned absorber $\mathrm{A} *$ is greater than 2 is depending on the fin density.

The Reynolds number in the flow duct is defined as 
$R_{e}=4 m_{A} L /(A * \eta)$

The semi-annular fins formulae have been used for calculate the fin surface area, heat transfer rate and efficiencies.

$$
\begin{aligned}
& \eta_{o}=q_{\text {total }} / q_{\max } \\
& =\left(q_{p}+q_{f}\right) /\left(h\left(A_{p}+A_{f}\right)\left(T_{0}-T_{\infty}\right)\right) \\
& \eta_{o}=1-A_{f}\left(1-\eta_{f}\right) / A \\
& q_{\text {total }}=q_{p}+q_{f}=h A_{p}\left(T_{0}-T_{\infty}\right) \\
& +h A_{f} \eta_{f}\left(T_{0}-T_{\infty}\right) \\
& =h\left(A_{p}+\eta_{\mathrm{f}} \mathrm{A}_{\mathrm{f}}\right)\left(T_{0}-T_{\infty}\right)
\end{aligned}
$$

Where,

$$
A=A_{p}+A_{f}
$$

$\mathrm{A}_{\mathrm{p}}+\pi \mathrm{d}_{0}\left(\mathrm{~L} 1-\delta \mathrm{N}_{\mathrm{f}} \mathrm{L}_{1}\right) \quad \mathrm{N}_{\mathrm{t}}+2\left(\left(\mathrm{~L}_{2} \mathrm{~L}_{3}-\right.\right.$ $\left.\pi \mathrm{d}_{0}^{2} \mathrm{~N}_{\mathrm{t}}\right) / 4$ )

$$
\begin{aligned}
& A_{f}=\left[2 \pi\left(d^{2}{ }_{e}-d^{2}{ }_{0}\right) / 4+\pi d_{e} \delta\right] N_{f} L_{1} N_{t} \\
& A_{e f f}=A_{p}+\eta_{f} A_{f} \\
& \eta_{f}=\left\{a\left(m t_{e}\right)^{-b} \text { for } \varphi>0.6+2.257\left(t^{*}\right)^{-0.445}\right. \\
& a=\left(t^{*}\right)^{-0.246} \varphi={ }_{m} l_{e}\left(t^{*}\right)^{n} n=\exp \left(0.13 m_{e}-\right. \\
& 1.3863) \\
& m=\left(2 h / k_{f} \delta\right)^{1 / 2} \quad l_{e}=l_{f}+\delta / 2 r^{*}+d_{e} O
\end{aligned}
$$

\section{4. results and discussion}

Then the baffles arrangement were positioned on the absorber plate (Cfd results: $\mathrm{Q}=424 \mathrm{~W}, \mathrm{~T}_{\text {out }}=$ $46^{\circ} \mathrm{C}, \Delta \mathrm{P}=39 \mathrm{~Pa}$. Theoretical results: $\mathrm{Q}=416.9 \mathrm{~W}$, $\mathrm{T}_{\text {out }}=44^{\circ} \mathrm{C}, \Delta \mathrm{P}=31 \mathrm{~Pa}$.) then changing the fin densities according to the results of pressure drop, heat transfer rate and outlet temperature. Similarly these values have been evaluated by help of theoretical results. In this analysis, the temperature output of standard SAH were getting $\mathrm{T}_{\text {out }}=43.346^{\circ} \mathrm{C}$ from Analytical result. Here the minimum 46 fins required to get the minimum temperature raise of $2^{\circ} \mathrm{C}$ from SAH with baffles. (Cfd results: $\mathrm{Q}=612 \mathrm{~W}$,
$\mathrm{T}_{\text {out }}=48^{\circ} \mathrm{C}, \Delta \mathrm{P}=49 \mathrm{~Pa}$. Theoretical results: $\mathrm{Q}=639$ $\left.\mathrm{W}, \mathrm{T}_{\text {out }}=51^{\circ} \mathrm{C}, \Delta \mathrm{P}=36 \mathrm{~Pa}\right)$. The maximum limit has decided due to the pressure drop limit of $80 \mathrm{~Pa}(\mathrm{Cfd}$ results: $\mathrm{Q}=1109 \mathrm{~W}, \mathrm{~T}_{\text {out }}=68.8^{\circ} \mathrm{C}, \Delta \mathrm{P}=79 \mathrm{~Pa}$. Theoretical results: $\mathrm{Q}=1025 \mathrm{~W}, \mathrm{~T}_{\text {out }}=64.17^{\circ} \mathrm{C}, \Delta \mathrm{P}=$ $76 \mathrm{~Pa}$ ). The results are shown in the given graphs 6(a)-(c). In this paper, a mathematical optimization tool was used to optimize the number of fins arrangements in SAH.

Graphical method:

$\operatorname{Min} Z=46 x+127 y$

Constrains,

$200 X 1+49 X 2 \leq 313$

$125 X 2+79 X 2 \leq 331$

In equations (22), (23) the values 200 and 125 are offset distances of fins, 46 and 79 are the pressure drop values. 313 and 331 are heat transfer rates. Both these values were taken from minimum and maximum fins (127 and 46 fins). After solving these equation the optimized value got is 72 fins ( $\mathrm{Cfd}$ results: $\mathrm{Q}=904.5 \mathrm{~W}, \mathrm{~T}_{\text {out }}=60^{\circ} \mathrm{C}, \Delta \mathrm{P}=52.5 \mathrm{~Pa}$. Theoretical results: $\mathrm{Q}=746 \mathrm{~W}, \mathrm{~T}_{\text {out }}=54^{\circ} \mathrm{C}, \Delta \mathrm{P}=$ 50.2Pa). The temperature and pressure drop profile diagram of optimized design is shown in figure 8(a)(b). In graphs 7(a)-(c) there were some sudden temperature raise in temperature output and heat transfer rate.

For the same intensity the temperature differences between Type I and Type II absorber plates were getting the huge temperature differences. At 940 $\mathrm{W} / \mathrm{m}^{2}$ intensity the air outlet temperature in Type I absorber plate (with obstacles) was around $68^{\circ} \mathrm{C}$. In Type II (without obstacles) it was only around $63^{\circ} \mathrm{C}$. The temperatures obtained from $\mathrm{Cfd}$ and Calculation were $60^{\circ} \mathrm{C}$ and $54^{\circ} \mathrm{C}$ respectively. Pressure drop measured between the inlet and outlet was 59.6 Pa. Cfd and Theoratical pressure drop values were 52.5 $\mathrm{Pa}$ and 50.2 Pa respectively. 

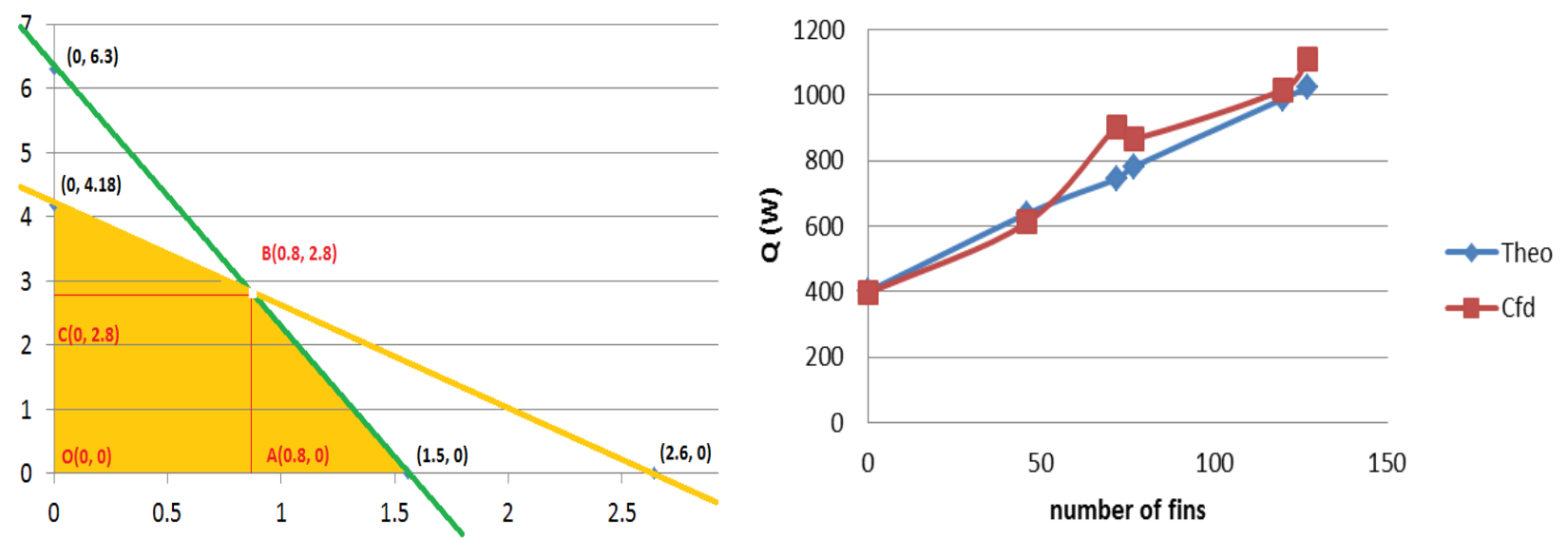

Fig. 6 .Graphical optimization method

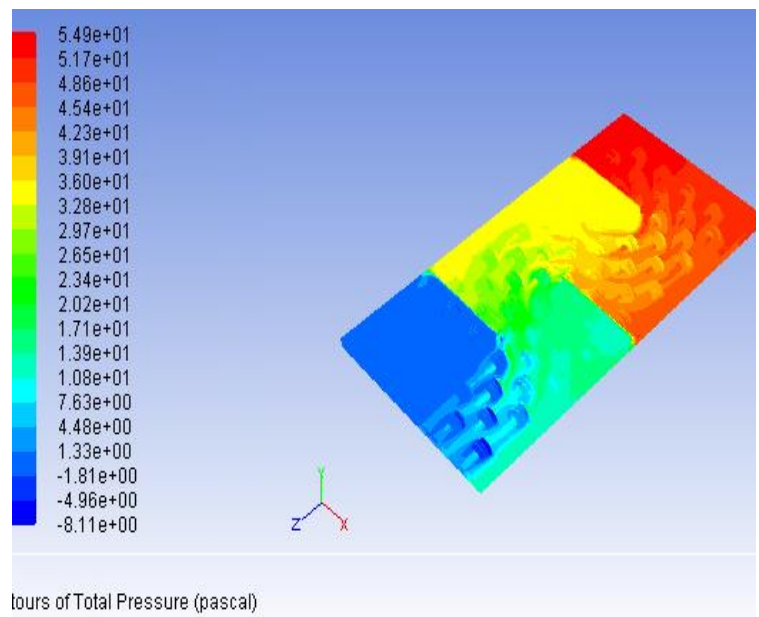

Fig. 8. (a) Temperature profile diagram

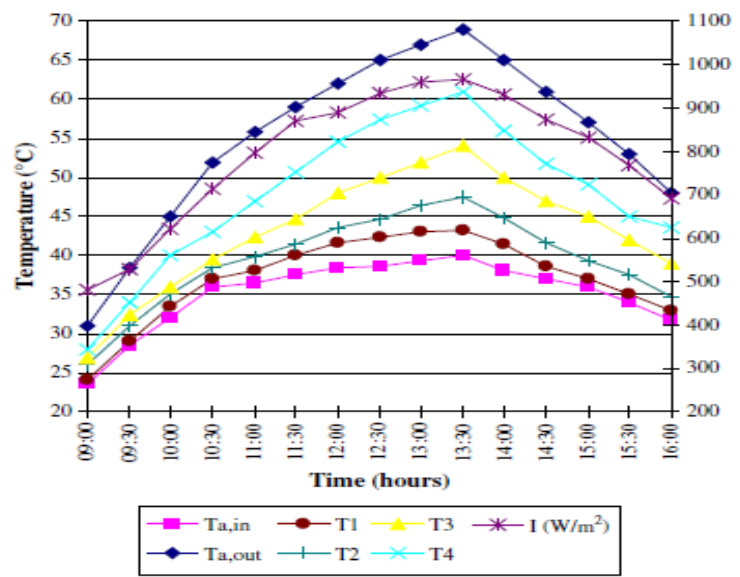

Fig. 9. Temp. variation of optimized collector

\section{Conclusion}

The surface of the absorber is the most important

Copyright $(\subset)$ Authors
Fig. 7(c) No. of fins Vs Pressure drop at $\mathrm{m}=0.03 \mathrm{~kg} / \mathrm{s}$

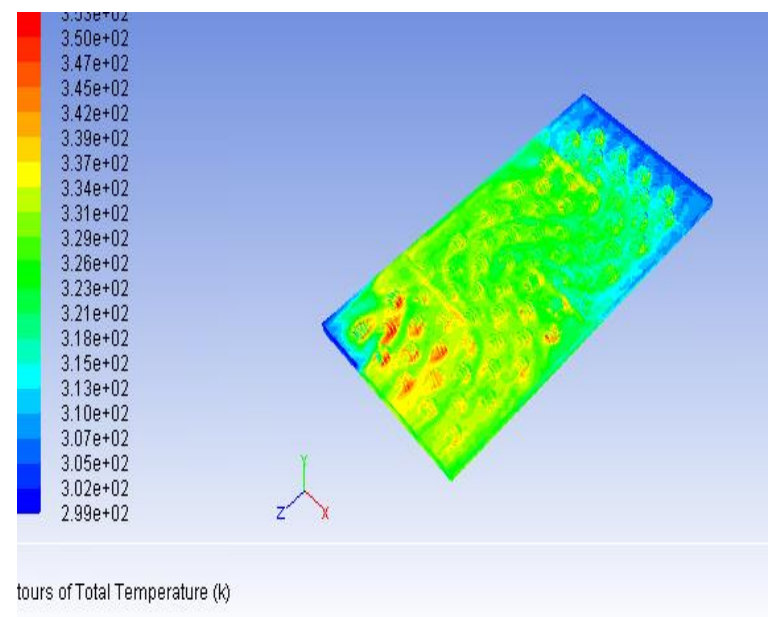

Fig. 8 .(b) pressure profile diagram.

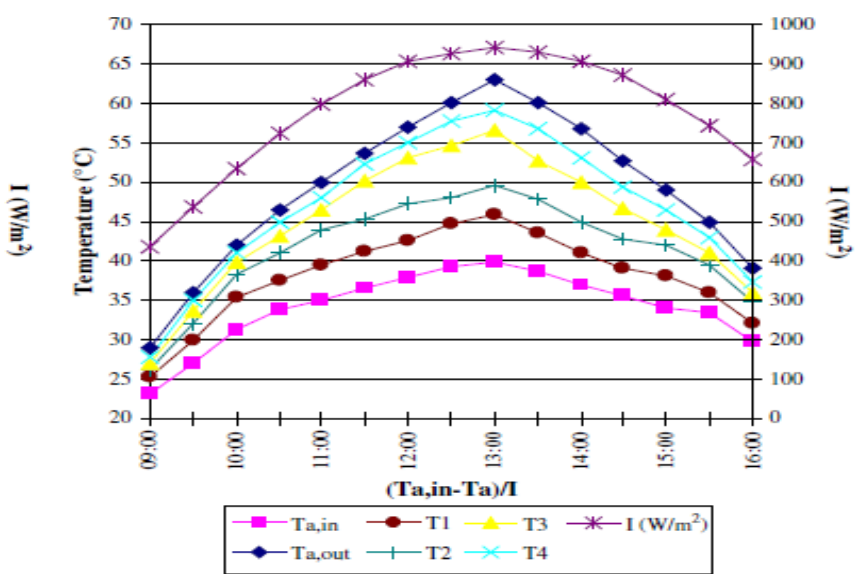

Fig. 10. Temp. variation of standard collector

part of the AHSD. It consist of 72 Modified annular fins and stainless steel air flow channels painted by 
black color and AHSD consist of no fins painted by some different black color. Modified annular fins inner diameter is $0.0188 \mathrm{~m}$ and outer diameter 0.0288 $\mathrm{m}$. In the MAF three more fins were used with the patch of $0.01 \mathrm{~m}$. The outlet temperature and pressure drop of SAH were determined by changing the fin densities with the help of software tool FLUENT. The analysis result shows that the outlet temperature is more and pressure drop was less in the case of SAH with obstacles when compared to the SAH without obstacles.

\section{References}

[1] C.D. Ho, H.M. Yeh, R.C. Wang, Heat-transfer enhancement in double-pass flat-platesolar air heaters with recycle, Energy 30 (15) (2005) 27962817.

[2] Mohamad AA. High efficiency solar air heater. Solar Energy 1997;60(2):71-6.

[3] F. Ozgen, M. Esen, H. Esen, Experimental investigation of thermal performance of adoubleflow solar air heater having aluminium cans, Renewable Energy 34 (11)(2009) 2391-2398.

[4] H. Esen, Experimental energy and exergy analysis of a double-flow solar air heaterhaving different obstacles on absorber plates, Building and Environment 43(2008) 1046-1054.

[5] C. Choudhury, H.P. Garg, J. Prakash, Design studies of packed-bed solar air heaters, Energy Conversion Manage 34 (2) (1993) 125-138.

[6] Y. Demirel, S. Kunc, Thermal performance study on a solar air heater with packed flow passage, Energy Conversion Manage 27 (1987) 317-325.

[7] Experimental investigation of thermal performance of a double-flow solar air heater having aluminium cans Filiz Ozgen, Mehmet Esen, Hikmet Esen Renewable Energy 34 (2009) 2391-2398

[8] Experimental investigation of thermal performance of solar air heater havingdifferent obstacles on absorber plates Ebru Kavak Akpinar, Fatih Koçyiğit, International Communications in Heat and Mass Transfer 37 (2010) 416-421

[9] F. Ozgen, M. Esen, H. Esen, Experimental investigation of thermal performance of adoubleflow solar air heater having aluminium cans, Renewable Energy 34 (11)(2009) 2391-2398.

[10] W. Leiner and M. Fiebig“ second law optimization of flat-plate solar air heaters", Solar Energy Vol.41, No. 2, pp. (1988) 127-132
[11]R. K. Shah and A. C. London, Laminar flow forced convection in ducts. Advances in Heat Transfer. Academic Press, New York (1978).

[12]Ramesh K. Shah and Dušan P. Sekulic "Fundamentals of heat exchanger Design" Handbook, Wiley publications 